\title{
Lung and bladder cancer in a Norwegian municipality with iron and steel producing industry: population based case-control studies
}

\author{
Tom K Grimsrud, Hilde Langseth, Anders Engeland, Aage Andersen
}

\begin{abstract}
Objectives-To investigate the influence of occupation on the rising incidence of lung and bladder cancer among men in a Norwegian municipality where an iron and steel plant constituted the key industry between 1955 and 1989.

Methods-Based on the lung cancer cases reported to the Cancer Registry of Norway from 1980 to 1992 a population based case-control study was performed, including 86 cases and 196 controls. Information on occupations and smoking habits was collected through interviews and from the personnel files from the industrial plants. A case-control study on bladder cancer with 52 cases and 156 controls was carried out to cast light on the role of polycyclic aromatic hydrocarbons (PAHs).

Results-An odds ratio (OR) for lung cancer of $2.9(95 \%$ confidence interval $(95 \%$ CI) 1.2 to 6.7) was associated with exposure to PAHs. Based on data from personnel files, increased risk of lung cancer (OR $2.895 \%$ CI 1.1 to 7.0 ) was associated with work experience in the pig iron department at the ironworks. A non-significant OR of 1.8 was associated with exposure to asbestos. Bladder cancer was not associated with exposure to PAHs at the iron, steel, and coke plant, or with experience from any of the production departments at the plant.

Conclusions-One fifth of the lung cancer cases were attributed to exposure to PAHs or asbestos. More than $80 \%$ of the cases of lung cancer were attributed to tobacco smoking. The cancer risk in the pig iron department may be due to a combination of exposures to PAH, asbestos, or dust of mixed composition.
\end{abstract}

The Cancer Registry of Norway, Institute for Epidemiological Cancer Research, Oslo, Norway T K Grimsrud

$\mathrm{H}$ Langseth

A Engeland

A Andersen

Correspondence to: Dr Tom K Grimsrud, The Cancer Registry of Norway, Institute for Epidemiological Cancer Research, N-0310 OSLO, Norway.

Accepted

27 November 1997 ern Norway, rose steadily during the period 1980-92, exceeding the national rate without any sign of stabilisation (figure). Primarily this would be expected to be a result of differences in the habit of tobacco smoking, which is recognised as the dominant cause of lung cancer world wide. Occupational exposures constitute another important risk factor investigated in several population based case-control studies during the past 10 to 20 years. In some regions and periods as many as $40 \%$ of the cases of lung cancer have been attributed to occupation.

Cancer of the urinary bladder is the fourth most frequent form of cancer in Norwegian men, and it is the second most frequent of the cancers associated with smoking. ${ }^{1}$ The incidence among men in Rana has been increasing, although not with the same clear trend as lung cancer (figure). Occupational exposures are also considered to be important risk factors in this disease, with as much as $24 \%$ of the cases attributed to occupation in some periods and geographical regions. ${ }^{2}$

During the postwar years the commercial centre of Rana developed into an industrialised town after the establishment of an iron and steel plant. The plant came into production in 1955 with three main departments delivering pig iron, steel ingots, and rolled products. A separate coke plant was operated from 1964. Until the plants were closed down in the late 1980s they together constituted the largest workplace in the region, employing more than 3500 workers, some $40 \%$ of all adult men in the municipality.

Asbestos has been widely used as an insulating material in industrial buildings and technical installations. The risk of lung cancer and pleural mesothelioma caused by inhalation of asbestos fibres is well recognised. ${ }^{3}$ Several authors have reported an increased risk of lung cancer among workers in iron, steel, and coke production. ${ }^{4-9}$ Exposure to polycyclic aromatic hydrocarbons (PAHs) is one of the suspected causes of cancer in these industries. The PAHs are also thought to cause bladder cancer among certain groups of industrial workers. ${ }^{4} 10$

The main purpose of the present investigation was to identify occupational risk factors possibly contributing to the incidence of lung cancer among men in Rana. The bladder cancer study was performed to elucidate the potential association between bladder cancer and occupational exposure to PAHs, and thereby identify a possible common cause of these two diseases. Thirdly, we wanted to 


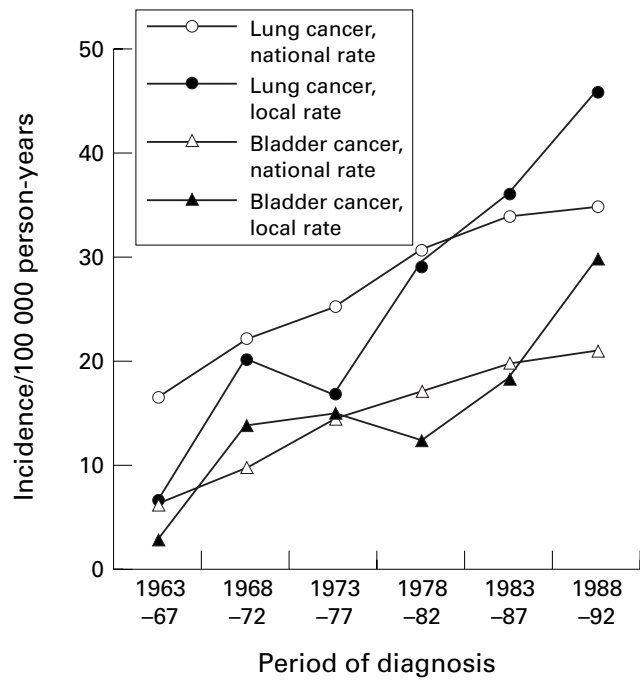

Age adjusted incidence (world standard population) of lung and bladder cancer among men in Norway and the municipality of Rana. The numbers of new cases of lung and bladder cancer in Rana during the last five year period were 42 and 27, respectively.

explore the possibilities of performing an in depth study based on registry data with increased cancer incidence in a small municipality.

\section{Material and methods}

This paper refers to two separate case-control studies. The first one on lung cancer was based on information traced in the personnel files at the iron, steel, and coke plant, and a complete history of occupations and smoking habits collected through interviews. In the second study on bladder cancer no interviews were performed due to few cases. This study was based on information from the personnel files only.

\section{STUDY SUBJECTS AND COLLECTION OF} INFORMATION

Lung cancer

All incident cases of lung cancer (88 cases) registered among male residents in Rana during the period 1 January 1980 to 31 December 1992 were selected. For each case three controls were drawn from the general population in the municipality among living residents on 1 January 1993 and deceased persons with Rana as their last place of residence as noted by the office of the national registrar. The controls were matched to each case according to sex and year of birth (same, previ-

Table 1 Information on interviews in the lung cancer study

\begin{tabular}{|c|c|c|c|c|}
\hline & \multicolumn{2}{|c|}{ Cases } & \multicolumn{2}{|c|}{ Controls } \\
\hline & n & $\%$ & $n$ & $\%$ \\
\hline \multicolumn{5}{|l|}{ Person interviewed: } \\
\hline Self respondent & 7 & 8.1 & 151 & 77.0 \\
\hline Spouse & 34 & 39.5 & 18 & 9.2 \\
\hline Child, sibling, or parent & 41 & 47.7 & 23 & 11.7 \\
\hline Others & 4 & 4.7 & 4 & 2.0 \\
\hline Total & 86 & 100 & 196 & 100 \\
\hline \multicolumn{5}{|l|}{ Interview situation: } \\
\hline Office & 59 & 68.6 & 143 & 73.0 \\
\hline Residence & 7 & 8.1 & 31 & 15.8 \\
\hline Telephone & 20 & 23.3 & 22 & 11.2 \\
\hline Total & 86 & 100 & 196 & 100 \\
\hline
\end{tabular}

ous, or next year). The controls should be free of lung cancer and living in the municipality at the time of diagnosis of the case.

Information on occupational history was collected from two sources: (a) through tracing subjects in the personnel files at the iron, steel, and coke plant, and $(b)$ through personal interviews with subjects or their next of kin. Time of employment, department, and when available, details on section and job were extracted from the employment files. All interviews were performed by one interviewer who followed a questionnaire covering occupations held for more than one year, lifetime smoking habits with times of starting and stopping and tobacco consumption, dietary habits, education, and residential history.

Lung cancer in women was not included in the study because of the few cases occurring during the same period ( 29 cases), and because the rise in incidence had not been as strong as in the men. Also participation of women in industrial work was negligible before 1975 .

More than $90 \%$ of the cases of lung cancer were deceased at the time of the study, whereas more than $75 \%$ of the interviewed controls were alive. The next of kin invited for interview were chosen in the following rank of priority: wife, child, sibling, other relative, or another person with good knowledge of the subject. If a case or his nearest next of kin refused to participate consent was sought to interview another relative. This gave satisfactory answers to the questionnaire from 86 out of 88 cases. Three extra controls were added to the 264 originally selected to ensure a minimum of one control per case. A total of 63 controls refused to participate, and five controls matched to the two cases with insufficient data were excluded from the analyses. This left 86 cases and 196 controls for the final study population. Most cases $(72 \%)$ were born between 1910 and 1929. The median age at diagnosis was 64 years. The interviews were conducted in an office in the town centre, alternatively in the subject's residence, or by telephone (table 1).

The occupational exposures of greatest initial interest were asbestos and PAHs. Exposures in the coke plant had been studied earlier by Romundstad et al based on environmental measurements and interviews with previous workers (unpublished observations). Estimates from their study were applied to the coke workers included in the present investigations.

At the iron and steel plant the indoor air concentration of PAHs was recorded only once in 1976 with 25 personal measurements by the National Institute of Occupational Hygiene. ${ }^{11}$ Inquiries were undertaken during the present study among old and experienced workers and administrative personnel to get more information on possible exposures to PAHs, asbestos, and other known carcinogens. The main sources of exposure to PAHs at the iron and steel plant were in the smelter section of the pig iron department. The insides of six large electric smelters (diameter 12 to $16 \mathrm{~m}$ ) were covered with a thick layer of a paste mixed from coal tar pitch and coke. Coal tar pitch was also used in the Söderberg electrodes of the same 
Table 2 Criteria for assignment of exposure to polycyclic aromatic hydrocarbons (PAHs) and asbestos

$\begin{array}{cl}\begin{array}{c}\text { Subjects with one or more of the following occupational experiences were considered exposed to PAHs: } \\ \text { PAHs1 }\end{array} & >1 \mathrm{y} \text { at the local iron and steel plant, and known experience as smelter } \\ & \text { worker in the pig iron department, alternatively pig iron worker without } \\ & \text { further specification } \\ & >1 \mathrm{y} \text { at the local coke plant and exposed to PAH according to industrial } \\ \text { hygienist } & >1 \mathrm{y} \text { as a production worker at another iron and steel plant } \\ \text { PAHs2 } & >1 \mathrm{y} \text { as a production worker at an aluminium plant } \\ \text { PAHs3 } & >1 \mathrm{y} \text { as a chimney sweep or in the fire brigade } \\ \text { PAHs4 } & >1 \mathrm{y} \text { as a stoker on a railway engine or ship } \\ \text { PAHs5 } & >1 \mathrm{y} \text { at the local iron and steel plant, and ever engaged in the mason } \\ \text { PAHs6 } & \text { department, or engaged with mechanical or electrical maintenance within } \\ \text { Subjects with one or } & \text { more of the following occuational expriences were considered exposed to asbestos } \\ \text { Asb1 } & \text { the pig iron department, the steel production department, or the rolling mill } \\ & >1 \mathrm{y} \text { at the local coke plant and exposed to asbestos according to industrial } \\ \text { Asb2 } & >1 \mathrm{y} \text { as a plumber } \\ \text { Asb3 } & >1 \mathrm{y} \text { as a stoker } \\ \text { Asb4 } & >1 \mathrm{y} \text { as a welder or fitter at a shipyard } \\ \text { Asb5 } & \end{array}$

smelters and in surface protection at some other places in the smelter section.

All subjects who had ever been working at the pig iron smelter section were considered exposed to PAHs. Workers with employment at the pig iron department without further specification of place of work, were also considered to be exposed. Workers only employed elsewhere were considered to be unexposed to PAHs at the iron and steel plant. Classification of occupational activities outside this industry was performed on the basis of job titles and information on employer. The occupations were selected with the purpose of identifying exposed subjects with high specificity and low sensitivity (table 2). The classification of occupations was performed without knowledge of case or control status.

Workers at the iron and steel plant who had been employed in the mason department, or with mechanical or electrical maintenance within the heat producing departments were considered exposed to asbestos dust. Table 2 shows the complete set of criteria for assignment of asbestos exposure. The nickel and chromium content measured in the pig iron was considered negligible (reported $<0.02 \%$ in 1980).

Table 3 Risk of lung cancer by smoking habits and occupational exposures to asbestos and $P A H^{*}$

\begin{tabular}{|c|c|c|c|c|c|}
\hline \multirow[b]{2}{*}{ Exposure } & \multicolumn{2}{|c|}{ Unadjusted $t$} & \multicolumn{2}{|c|}{ Adjusted $\ddagger$} & \multirow{2}{*}{$\begin{array}{l}\text { Cases/controls } \\
\text { (n) }\end{array}$} \\
\hline & $O R$ & $95 \% C I$ & $O R$ & $95 \% C I$ & \\
\hline \multicolumn{6}{|l|}{ Smoking habits: } \\
\hline Never smokers & 1.0 & Control & 1.0 & Control & $3 / 34$ \\
\hline \multicolumn{6}{|c|}{ Former smokers ( $\mathrm{kg}$ consumed) } \\
\hline $1-74$ & 1.1 & 0.2 to 5.4 & 1.4 & 0.3 to 8.1 & $4 / 51$ \\
\hline $75-149$ & 2.1 & 0.4 to 11 & 2.3 & 0.4 to 13 & $4 / 18$ \\
\hline$\geqslant 150$ & 7.2 & 1.6 to 32 & 9.2 & 1.9 to 44 & $8 / 8$ \\
\hline \multicolumn{6}{|c|}{ Current smokers (kg consumed) } \\
\hline $1-74$ & 3.6 & 0.8 to 16 & 5.2 & 1.1 to 25 & $10 / 31$ \\
\hline $75-149$ & 6.3 & 1.5 to 25 & 7.3 & 1.6 to 33 & $14 / 20$ \\
\hline$\geqslant 150$ & 14 & 3.7 to 56 & 21 & 4.8 to 89 & $43 / 34$ \\
\hline \multicolumn{6}{|c|}{ Occupational exposures: } \\
\hline Asbestos & 1.5 & 0.7 to 3.4 & 1.8 & 0.7 to 4.6 & $13 / 18$ \\
\hline $\mathrm{PAHs}$ & 2.2 & 1.1 to 4.4 & 2.9 & 1.2 to 6.7 & $18 / 18$ \\
\hline
\end{tabular}

${ }^{\star}$ Criteria for assignment of exposures as for table 2 .

†Effect of smoking habits unadjusted for occupational exposures, and vice versa.

$\ddagger$ Effect of smoking habits adjusted for occupational exposures, and vice versa.

SStopped smoking $>5 \mathrm{y}$ before date of diagnosis of the case.

I1 Cigarette is counted as equivalent to $1 \mathrm{~g}$ tobacco, thus 75 and $150 \mathrm{~kg}$ correspond to 10.3 and 20.5 pack-years, respectively.
Bladder cancer

The bladder cancer study included all 52 incident cases registered by the cancer registry among male residents of Rana during the period 1 January 1980 to 31 December 1992 . For each case three controls were drawn from criteria corresponding to those used in the lung cancer study. Occupational history for the subjects was traced in the personnel files at the iron, steel, and coke plant. No information on smoking habits or occupational activity outside these industries was available. Exposure to PAHs was assigned to the subjects according to the matrix used in the lung cancer study (table 2 ). Most of the cases of bladder cancer (73\%) were born between 1910 and 1929. The median age at diagnosis was 68 .

\section{STATISTICAL ANALYSIS}

Odds ratios (ORs) and their 95\% confidence intervals (95\% CIs) were derived from conditional logistic regression models, as appropriate for matched case-control studies, from the program package EGRET. ${ }^{12}{ }^{13}$ Odds ratios for lung cancer were estimated according to history of smoking, exposure to asbestos and PAHs, and according to work experience from the coke plant and the three main production departments at the iron and steel plant. The total amount of tobacco smoked until diagnosis of the case was calculated for all smokers. Subjects who had stopped smoking five or more years before diagnosis of the case were called former smokers. The bladder cancer material was only analysed according to department and exposure to PAHs within the iron, steel, and coke plant.

\section{Results}

LUNG CANCER

To obtain a good adjustment for smoking, different models were explored for risk of lung cancer. The goodness of fit was evaluated without adjustment for occupational exposures. The best model was based on smoking status five years before the date of diagnosis of the case and lifetime tobacco consumption until date of diagnosis. A single variable with seven levels (never smoker, former smoker $(1-74 \mathrm{~kg}$, $75-149 \mathrm{~kg}$, and $\geqslant 150 \mathrm{~kg}$ ), and current smoker (1-74 kg, 75-149 kg, and $\geqslant 150 \mathrm{~kg}$ )) was used. Adjustment for smoking was performed by including this variable in the regression model.

Table 3 shows the risks of lung cancer according to smoking habits and exposure to asbestos or PAHs. The OR associated with exposure to PAHs was 2.9 (95\% CI 1.2-6.7). The OR related to asbestos exposure was increased but not significant. A possible interaction between exposure to asbestos and PAHs was tested but was found to be not significant.

Only two of the lung cancer cases and nine controls had been working for more than one year at the coke plant, and there was no increased risk associated with this work experience (data not shown). Employment in the three main production departments at the iron and steel plant was more common. To explore the association between cancer and 
Table 4 Risk of lung cancer by employment at the pig iron department (PID), with and without adjustment for smoking habits

\begin{tabular}{|c|c|c|c|c|c|}
\hline & \multicolumn{2}{|c|}{ Unadjusted } & \multicolumn{2}{|c|}{ Adjusted } & \multirow[b]{2}{*}{ Cases/controls ( $n$ ) } \\
\hline & $O R$ & $95 \% C I$ & $O R$ & $95 \% C I$ & \\
\hline Never employed at ISP^ ${ }^{\star}$ or employed for $\leqslant 1 \mathrm{y}$ & 1.0 & Control & 1.0 & Control & $48 / 125$ \\
\hline Employed at ISP for $>1 \mathrm{y}$ but never at the PID & 1.1 & 0.6 to 2.0 & 0.9 & 0.4 to 1.8 & $22 / 53$ \\
\hline Employed at ISP for $>1 \mathrm{y}$ and employed at the PID & 2.3 & 1.1 to 4.8 & 2.8 & 1.1 to 7.0 & $16 / 18$ \\
\hline
\end{tabular}

${ }^{\star} \mathrm{ISP}=$ iron and steel plant.

work in these three departments, the subjects were divided in the following way: a constant control group was constructed consisting of all subjects with no or negligible employment at the iron and steel plant (one year or less). The rest of the subjects (iron and steel workers with more than one year's employment) were further divided into two subgroups: one group of workers with experience from the department in question (exposed group), and a control group of workers without any employment in this particular department.

Iron and steel workers with experience from the pig iron department had an OR for lung cancer of 2.8 (95\% CI 1.1-7.0) compared with subjects with no or negligible employment at the ironworks (table 4). No increased risk for lung cancer was associated with employment in the steel production department or in the rolling mill (data not shown).

Some subjects had been exposed to PAHs and asbestos in jobs outside the iron, steel, and coke plant (table 2, criteria PAHs 3-6 and asbestos 3-5), some subjects were considered exposed within this plant (table 2, criteria PAHs 1-2 and asbestos 1-2), and some had been exposed in both these situations due to change of jobs. An analysis was undertaken to assess the separate effect according to place of exposure. The risk associated with exposures outside the iron, steel, and coke plant was more pronounced than the risk from exposures within the works, although the difference was not significant (table 5).

\section{BLADDER CANCER}

There was no sign of increased risk of bladder cancer associated with exposure to PAHs within the iron, steel, and coke plant (table 6). Only two bladder cancer cases and eight controls had been working more than one year

Table 5 Risk of lung cancer by exposure to asbestos or PAHs, alone or in combination, at different workplaces with and without adjustment for smoking habits

\begin{tabular}{|c|c|c|c|c|c|}
\hline \multirow[b]{2}{*}{ Exposure } & \multicolumn{2}{|c|}{ Unadjusted } & \multicolumn{2}{|c|}{ Adjusted } & \multirow{2}{*}{$\begin{array}{l}\text { Cases/ } \\
\text { controls (n }\end{array}$} \\
\hline & $O R$ & $95 \% C I$ & OR & $95 \% C I$ & \\
\hline Unexposed & 1.0 & Control & 1.0 & Control & $59 / 165$ \\
\hline Exposed at ISCP ${ }^{\star}$ only & 1.5 & 0.7 to 3.1 & 1.9 & 0.8 to 4.6 & $13 / 25$ \\
\hline Exposed at other workplaces only & 5.1 & 1.7 to 15 & 6.2 & 1.6 to 24 & $10 / 5$ \\
\hline Exposed both at ISCP and other workplaces & 8.5 & 0.9 to 79 & 20 & 1.5 to 280 & $4 / 1$ \\
\hline
\end{tabular}

^ISCP=iron, steel, and coke plant.

Table 6 Risk of bladder cancer by exposure to PAHs at the iron, steel, and coke plant (ISCP)

\begin{tabular}{llll}
\hline Employment and exposure & OR & $95 \%$ CI & Cases/controls (n) \\
\hline Never employed at ISCP or employed for $\leqslant 1$ y & 1.0 & Control & $29 / 92$ \\
Employed at ISCP for $>1$ y but not exposed to PAHs & 1.4 & 0.7 to 2.9 & $20 / 45$ \\
Employed at ISCP for $>1$ y and exposed to PAHs & 0.5 & 0.1 to 1.9 & $3 / 19$ \\
\hline
\end{tabular}

at the cokeworks, and there was no increased risk of bladder cancer connected with general employment at this plant. Neither was there any sign of increased risk associated with employment in the three production departments at the iron and steel plant (data not shown).

\section{Discussion}

The present population based studies were conducted by selecting cancer cases in a small area through a period of 13 years. Increased risk of lung cancer was associated with work in the pig iron department at the iron and steel plant, a cancer risk not identified before. There was a significant association between risk of lung cancer and exposure to PAHs based on job titles from interviews and information from personnel files.

The population in a municipality is a dynamic cohort, and this type of study is vulnerable to migration. The number of residents in the district was 9000 in 1946, culminating in 1974 with 26000 , and subsequently slightly reduced to 25000 in 1992. The population thus seemed to be stable during the years when the cancer cases occurred. A selection bias could still be introduced as the controls were drawn from an updated population registry from 1 January 1993, whereas the cancer cases were reported among residents over a long period. An evaluation of changes of address and alterations in the number of residents recorded by the office of the national registrar indicated that only $6 \%$ of men born between 1910 and 1934 moved out of the district during the period 1986-92. This birth cohort includes about $80 \%$ of the cases in the lung and bladder cancer studies. It is therefore difficult to think that this low grade migration, even if differential to some extent, could produce the high ORs found within subgroups of workers in the present study. Some of the industrial employees were known to be residents of the neighbouring municipalities all their lives, a fact that could lead to a loss of cases and reduce the chances of identifying an industrial cancer risk.

The low cancer incidence in the municipality before 1980 can be explained, in part, by the prevailing jobs of the male population. Before industrialisation, the district was rural with farming and fishing as the main occupational activities. Fifty three per cent of the lung cancer controls included in the analyses had worked for one or more years in agriculture, fishing, or forestry work. These trades are recognised as having a low risk of lung cancer, perhaps with the exception of fishing. ${ }^{14}$ 
Nearly $25 \%$ of the controls refused to participate in the interviews. Participants as well as non-participants were traced in the personnel files at the iron, steel, and coke plant. There was only a minor difference between the prevalence of employment for more than one year in this industry when the total group of 267 controls was compared with the group of 196 controls used in the analyses (44\% v 40\%, respectively).

The inequality in source of information (self and proxy respondents) between cases of lung cancer and controls could introduce differential misclassification (table 1). Several authors have evaluated the validity of data collected from proxy respondents. Close relatives are generally found to give valid information on smoking status, although the accuracy about amount and duration is lower. ${ }^{15}$ Details on occupational history or exposures collected from next of kin can be of questionable quality, but information on job title, especially usual job or longest job held, can be satisfying. ${ }^{16}$ The use of interviewers seems to give more valid and reliable answers than self administered questionnaires. ${ }^{17-19}$

It is essential to point out that reports on employment at different work sites at the iron and steel plant were not subject to information bias, based as they were on data recorded many years before diagnosis. It is interesting to note that the job exposure matrix constructed to identify subjects exposed to PAHs and asbestos in the local industry did not produce stronger ORs than the analysis of risk associated with worksite on a coarse scale (tables 4 and 5). This may be due to chance or to misclassification through application of the matrix. There might also be important exposures that have not been included in the matrix.

Several authors have commented on the lack of good or general explanations of risk of lung cancer in the iron and steel industry, except for coke oven workers and foundry workers. ${ }^{50-22}$ The PAHs are often found to be present in different production steps, but exposure levels are generally low compared with those encountered in coke and aluminium production. ${ }^{23}$ The average exposure concentration of PAHs in the pig iron department in the present study was estimated to be $25 \mu \mathrm{g} / \mathrm{m}^{3}$ based on the 1976 recordings. This is less than the occupational exposure limit decided by the Norwegian Directorate of Labour Inspection $\left(40 \mu \mathrm{g} / \mathrm{m}^{3}\right) .^{24}$ However, during the first years of operation exposure levels at the ironworks probably were substantially higher, due to the quality of the raw materials containing tar pitch, the way of handling it, and the lack of mechanical ventilation. Even the measurements performed in 1976 indicated that some of the work tasks could lead to high short term exposures (570 $\mu \mathrm{g} / \mathrm{m})$. An analysis of the association between lung cancer and exposure to PAHs in the pig iron department during the first 10 production years only, gave a significant OR for lung cancer of 3.2 (95\% CI 1.0-12) (not shown in table). The long observation time may have added to the clarity of this association. The concentration of dust containing silica as well as the concentration of PAHs in the working atmosphere was known to be annoying during the early production years. This is a factor that may have contributed to the risk of cancer found at the smelters as well as at the rest of the pig iron department.

The criteria for categorisation of jobs as exposed or unexposed were chosen to provide a low sensitivity and a high specificity in the assignment of exposures. This gives a high probability of exposure really having occurred in the jobs called exposed (low number of false positive errors), but may include some truly exposed subjects among those called unexposed (false negative errors). In a community with low exposure prevalence this will tend to reduce the size of the non-differential misclassification bias, a bias expected to act towards unity. ${ }^{25}$

In the present study bladder cancer was not associated with exposure to PAHs or work in the iron, steel, and coke plant. This finding might change with a longer observation time. A study from a Norwegian aluminium smelter suggested that exposure to tar pitch volatiles had the strongest effect on lung and bladder cancer risk 30 to 40 years later. ${ }^{26}$ The lack of association between bladder cancer and exposure to PAHs did not support the indication that PAHs were the most important carcinogen for lung cancer. It is necessary, however, to be aware that no information on PAH exposure outside the iron, steel, and coke plant was available in the bladder cancer study. Besides, according to the literature a simultaneously increased risk of lung and bladder cancer is not always found in workers exposed to PAHs. ${ }^{47}$ This may be a result of different composition of the tar pitch, or other differences connected with exposure or uptake.

Several authors have found equally high risks of lung cancer associated with exposure to PAHs and asbestos, ${ }^{7228-33}$ but the lack of information on exposure levels forbids further comparison. Reports from American coke plants refer to exposure concentrations much higher than the those found at the Rana coke plant, where the highest average air concentration of PAHs was recorded during the 1970s, and was estimated to be $<300 \mu \mathrm{g} / \mathrm{m}^{3}$ for top side coke oven workers ( $P$ Romundstad, unpublished observations).

The percentage of controls who were considered exposed to asbestos corresponds well with figures from other Norwegian studies based on interviews or self reporting of moderate to heavy exposure. ${ }^{32} 34{ }^{35}$ However, only a single case of pleural mesothelioma was reported to the cancer registry from the municipality of Rana during the period from which the lung cancer cases were selected. This is one third of what should be expected from age adjusted national incidences.

Possibly the relatively high risk connected with exposures outside versus within the local iron, steel, and coke plant could reflect real differences in exposure. However, the high ORs could also be a result of differences in duration of follow up, as the iron and steel plant was not 
opened until 1955, limiting the observation time to a maximum of 37 years.

Based on the ORs and the number of cases in each exposure group the population attributable risk of lung cancer associated with exposure to PAHs, asbestos, or the combination of the two was calculated to be $21 \%$ with adjustment for smoking. ${ }^{36}$ In two other Norwegian studies the proportions attributed to occupation were $13 \%$ and $22 \%$ based on job titles regarded to have definite exposure to known or possible lung carcinogens. ${ }^{38}$ The population attributable risk associated with smoking in the present study was $83 \%$ when occupational exposures were adjusted for. The attributable risk confined to both smoking and occupation was $84 \%$.

In conclusion, occupational exposures seem to have had a certain impact on the lung cancer incidence in Rana during the observation period. The investigation proved to be rewarding even in a community with as few as 25000 inhabitants. Based on personnel files the study identified a cancer risk in the pig iron department, probably associated with exposure to PAHs. Other exposures, to asbestos or dust containing silica, may have contributed to the cancer risk. More than $80 \%$ of the lung cancer cases would have been prevented if exposure to tobacco smoke had been avoided.

This study was performed at the request of and with funds from the Municipality of Rana. Grants have also been received from the Norwegian Ministry of Industry and Energy, Norsk Jern Eiendom AS, and the Norwegian Cancer Society. We are grateful for valuable help and useful comments from our colleagues at the Cancer Registry of Norway.

1 Engeland A. Trends in the incidence of smoking-associated cancers in Norway, 1954-93. Int f Cancer 1996;68:39-46.

2 Vineis P, Simonato L. Proportion of lung and bladder cancers in males resulting from occupation: a systematic approach. Arch Environ Health 1991;46:6-15.

3 Overall evaluations of carcinogenicity: an updating of IARC Monographs volumes 1 to 42. IARC Monogr Eval Carcinog Risks Hum 1987; (suppl 7):1-440.

4 Polynuclear aromatic compounds, part 3: industrial exposures in aluminium production, coal gasification, coke production, and iron and steel founding. IARC Monogr Eval Carcinog Risks Hum 1984;34:1-271.

5 Blot WJ, Brown LM, Pottern LM, et al. Lung cancer among long-term steel workers. Am f Epidemiol 1983;117:706-16.

6 Moulin JJ, Portefaix P, Wild P, et al. Mortality study among workers producing ferroalloys and stainless steel in France. workers producing ferroalloys and
$B r \mathcal{F}$ Ind Med 1990;47:537-43.

7 Yamaguchi N, Kido M, Hoshuyama T, et al. A case-control study on occupational lung cancer risks in an industrialized city of Japan. $\mathscr{F p}$ F Cancer Res 1992;83:134-40.

8 Finkelstein MM. Lung cancer among steelworkers in Ontario. Am F Ind Med 1994;26:549-57.

9 Xu Z, Pan G-W, Liu L-M, et al. Cancer risk among iron and steel workers in Ashan, China, part I: proportional mortality ratio analysis. Am f Ind Med 1996;30:1-6.

10 Bonassi S, Merlo F, Pearce N, et al. Bladder cancer and occupational exposure to polycyclic aromatic hydrocarbons. Int $\mathcal{F}$ Cancer 1989; 44:648-51.

11 Biørseth A, Bjørseth O, Fieldstad PE. Kartlegging av PAH ved råjernverket, Norsk fernverk A/S (Polycyclic aromatic hydrocarbons in the working atmosphere). Oslo/Trondheim: SI, SINTEF, YHI, 1978. (In Norwegian.)

12 Breslow NE, Day NE. Statistical methods in cancer research. Vol 1. The analysis of case-control studies. Lyon: IARC, 1980.
13 EGRET Statistical Software. Seattle WA: Statistics and Epidemiology Research Corporation (SERC), 1988.

14 Kristensen P, Andersen A, Irgens LM, et al. Incidence and risk factors of cancer among men and women in Norwegian agriculture. Scand $\mathcal{F}$ Work Environ Health 1996; 22:14-26.

15 McLaughlin JK, Mandel JS, Mehl ES, Blot WJ. Comparison of next-of-kin with self-respondents regarding questions on cigarette, coffee, and alcohol consumption. Epidemiology 1990;1:408-12.

16 Lerchen ML, Samet JM. An assessment of the validity of questionnaire responses provided by a surviving spouse. Am 7 Epidemiol 1986;123:481-9.

17 Herrmann N. Retrospective information from questionnaires. I. Comparability of primary respondents and their next-of-kin. Am f Epidemiol 1985;121:937-47.

18 Herrmann N. Retrospective information from questionnaires. II. Intrarater reliability and comparison of questionnaire types. Am $\mathcal{F}$ Epidemiol 1985;121:948-53.

19 Blatter BM, Roeleveld N, Zielhuis GA, et al. Assessment of occupational exposure in a population based case-control study: comparing postal questionnaires with personal interviews. Occup Environ Med 1997;54:54-9.

20 Radford EP. Cancer mortality in the steel industry. Ann N Y Acad Sci 1976;271:228-38.

21 Finkelstein MM, Boulard M, Wilk N. Increased risk of lung cancer in the melting department of a second Ontario steel manufacturer. Am f Ind Med 1991;19:183-94.

$22 \mathrm{Xu} \mathrm{Z}$, Brown LM, Pan G-W, et al. Cancer risk among iron and steel workers in Ashan, China, part II: case-control studies of lung and stomach cancer. Am f Ind Med 1996;30:7-15

23 Lindstedt G, Sollenberg J. Polycyclic aromatic hydrocarbons in the occupational environment. Scand $\mathcal{F}$ Work Environ Health 1982;8:1-19.

24 Administrative normer for forurensning $i$ arbeidsatmosfere 1996 (Occupational exposure limits). Oslo, Norway: Directorate of Labour Inspection, 1996. (In Norwegian.)

25 Stewart WF, Correa-Villaseñor A. False positive exposure errors and low exposure prevalence in community-based errors and low exposure prevalence in community-based 40.

26 Rønneberg A, Andersen A. Mortality and cancer morbidity in workers from an aluminium smelter with prebaked carbon anodes-part II: cancer morbidity. Occup Environ Med 1995;52:250-4.

27 Rønneberg A, Langmark F. Epidemiologic evidence of cancer in aluminum reduction plant workers. Am f Ind Med 1992;22:573-90.

28 Pastorino U, Berrino F, Gervasio A, et al. Proportion of lung cancers due to occupational exposure. Int $\mathcal{f}$ Cancer 1984;33:231-7.

29 Pannett B, Coggon D, Acheson ED. A job-exposure matrix for use in population based studies in England and Wales. Br F Ind Med 1985;42:777-83.

30 Hinds MW, Kolonel LN, Lee J. Application of a job-exposure matrix to a case-control study of lung cancer. F Natl Cancer Inst 1985;75:193-7.

31 Kjuus $\mathrm{H}$, Skjærven R, Langård $\mathrm{S}$, et al. A case-referent study of lung cancer, occupational exposures and smoking. I. Comparison of title-based and exposure-based occupational information. Scand $\mathcal{F}$ Work Environ Health 1986;12: 193-202.

32 Kjuus H, Skjærven R, Langård S, et al. A case-referent study of lung cancer, occupational exposures and smoking. II. Role of asbestos exposure. Scand 7 Work Environ Health 1986;12:203-9.

33 Morabia A, Markowitz S, Garibaldi K, et al. Lung cancer and occupation: results of a multicentre case-control study. Br f Ind Med 1992;49:721-7.

34 Hilt B, Langård S, Lund Larsen PG, et al. Previous asbestos exposure and smoking habits in the county of Telemark Norway-a cross sectional population study. Scand $\mathcal{F}$ Work Environ Health 1986;12:561-6.

35 Bakke P, Gulsvik A, Eide GE, et al. Smoking habits and lifetime occupational exposure to gases or dusts, including asbestos and quartz, in a Norwegian community. Scand $\mathcal{F}$ Work Environ Health 1990;16:195-202.

36 Bruzzi P, Green SB, Byar DP, et al. Estimating the population attributable risk for multiple risk factors using case-control data. Am f Epidemiol 1985;122:904-14.

37 Kvåle G, Bjelke E, Heuch I. Occupational exposure and lung cancer risk. Int $\mathcal{F}$ Cancer 1986;37:185-93.

38 Kjuus $\mathrm{H}$, Langård $\mathrm{S}$, Skjærven $\mathrm{R}$, et al. A case-referent study of lung cancer, occupational exposures and smoking. III. Etiologic fraction of occupational exposures. Scand f Work Environ Health 1986;12:193-202. 